bitror. Verum equidem inquam ego non facile est Simonidi contradicere. sapieus enim et diuinus uir fuit. Sed quodeunque ille dixit fortasse quidem o Polemarche tu nosti. Ego autem non intelligo, nam perspicuum est eum non id dicere quod dudum a uobis dicebatur, quod scilicet reddendum est quod quispiam apud alium deposuerit atque etiam si insanus illud repetat. nam debetur id quod est depositum. Est ne scilicet? Reddendum igitur non est quandocunque is qui repetit sanus non fuerit. Recte quidem inquit. Aliud igitur quantum uidetur Simonides dicit, quod scilicet quae debeantur iustum est reddere. Aliud sane per Jouem. censet autem amicis bene mali autem nihil faciendum esse. Intelligo quidem inquam ego quod nequaquam id quod debet is exoluit quicunque aurum ei qui deposuit reddiderit si haec redditio futura est illi perniciosa amici autem sunt et qui reddit et qui accipit. Nunquid ais ita Simonidem dicere? Plane quidem. Quid autem reddendumne est inimicis quodcunque iis debitum

\title{
fol. 28. verso
}

fuerit? Omnino quidem inquit id quod illis debetur. Debetur autem ut arbitror inimico ab inimico quodquidem conueniens ma. Ium aliquod. Occulte igitur et poetice inquam ego Simonides quid eset iustum significauit. Intelligebat enim quantum licet prospicere quod id iustum foret quod esset unicuique conueniens reddere atque id debitum nominauit. Verum quid putas inquit? per Jovem inquam ego $\mathrm{Si}$ igitur illum quispiam interrogaret o Simonides quibus igitur quid conueniens et dignum ars distribuendo uocatur medicina quid existimas illum responsurum? Ma. nifestum inquit quia quae alimenta corporibus potiones et medicamenta praebet Quid autem quibus distribuendo ars coquinaria uocatur quae cibis condimeuta. Age ars quae aliquid aliquibus distribuet nominabitur iusticia. Siquidem inquit o Socrates oportet iis quae dudum a te dicta sunt non repugnare quae scilicet amicis commoda et utilitatem. inimicis autem damna et perniciem afferat.

Barcelona.

Ernst Volger.

\section{Die authentica der Berliner ausgabe des Aristoteles. (Nachtrag zu Philol. XII, p. 494 flgg.)}

In dem erwähnten aufsatz bemerkte ich (p. 495), der werth des daselbst beschriebenen buches werde dadurch geschmälert, dass, ,nicht immer aus allen handschriften, die im druck als benutzt erscheinen, die varianten eingetragen seien"; für die Plhy. sik, um die es dem verfasser zunächst zu thun war, galt dies von FK. - Seitdem ist es gelungen auch diese zu benutzen, da herr geh. rath Brandis uns seine Sylburgiana, in die er sie 
eingetragen hatte, zur benutzung anvertraut hat, mit jener güte und jenem nur auf das beste der wissenschaft gerichteten sinn den jeder erfahren der von dem würdigen mann je etwas zu erbitten hatte.

Die arbeit ist nun, was die physik anbelangt, beendigt; doch reut mich fast die zeit. Nicht als ob nicht auch für FK unser gedruckter apparat aus dem geschriebenen mannigfach berichtigt und bereichert würde: es ist fast keine seite wo nicht ein paar kleine versehen zu berichtigen wären; aber der text des Aristoteles, worauf es uns doch vornehmlich ankommt, der text wird durch alle diese kleinen varianten entwe. der gar nicht afficirt oder nur an drei bis vier stellen (eine frage die wir uns zu weiterer erwägung vorbehalten); so dass der gewinn nur gering genannt werden kann.

Die grundsätze nach denen Brandis seine collationen angestellt hat, sind im ganzen dieselben wie die Bekker'schen; nur ergiebt sich aus Brandis' verfahren ein mehr, welches jedoch Bekker, eben weil die entsprechenden beobachtungen für die von $i \mathrm{hm}$ übernommenen codices fehlten, für den gedruckten apparat nicht verwerthen konnte. Hieher gehört eine mit unglaublicher geduld festgehaltene aufmerksamkeit auf $\gamma \iota \gamma \nu-$ und $\gamma \iota v-$, auf $\alpha i \varepsilon \ell$ und $\alpha \varepsilon i$, auf ovं $\omega_{\zeta}$ vor consonanten und ähnliches. Ob ein codex eine lesart von erster oder von zweiter hand habe, ist sorgfältiger als bei Bekker notirt, daher denn letzterer vieles der art unter den Brandisschen notaten im druck weggelassen hat. Es braucht nicht gesagt zu werden, dass dies fast durchgängig mit urtheil und takt geschehen ist; gleichwohl entstehen daraus gewisse inconsequenzen, wesshalb wir vorziehen, die Brandis'schen notate wieder herzustellen, und bedauern nur, für die von Bekker angestellten collationen, eben weil jene notizen schon in seinem geschriebenen apparat fehlen, nicht dasselbe thun zu können.

So viel glaubten wir zur vervollständigung unsers früher gegebnen aufsatzes sagen zu müssen, damit jeder wisse was hier zu erwarten und besonders was nicht zu erwarten sei, und an wen er sich vorkommenden falls zu wenden habe. Im übrigen wird man es natürlich finden, dass wir ein in privatbesitz befindliches buch nicht in derselben weise benutzen wie es mit jenem andern, auf einer öffentlichen bibliothek zu jedermanns einsicht liegenden buche geschehen konnte. Was daraus für deu apparat der Naturalis Auscullatio gewonnen worden, wird später an seinem ort vollständig mitgetheilt werden, wozu uns durch die güte des herrn geh. rath Brandis die erlaubniss geworden ${ }^{1}$ ). Bremeu. Ad. Torstrik.

1) Es sei erlaubt, anhangsweise eine auzahl druckfehler anzugeben, die sich in den erwähnten früheren aufsatz eingeschlichen haben: 